\title{
O CONTROLE DA MOBILIDADE EM VARIÁVEIS LINGUÍSTICAS
}

\section{CONTROL OF MOBILITY IN LINGUISTIC VARIABLES}

\author{
Manoel Siqueira
}

Resumo: A mobilidade tem importante papel sobre o mecanismo de mudança linguística no português brasileiro (BORTONI-RICARDO, 1985, 2011; OUSHIRO, 2016). Em função da mobilidade, falantes entram em contato com variáveis linguísticas que não são de sua comunidade, levando-os a incorporá-las em seu repertório e a difundi-las em outras comunidades. Neste trabalho, objetivamos discutir o controle da mobilidade em variáveis linguísticas, de modo a compreender como, a partir do deslocamento e do contato, falantes podem mudar seu comportamento linguístico. O enfoque são estudos feitos com a amostra Deslocamentos (2019), do banco Falares Sergipanos (FREITAG, 2013), que considera a fala de universitários da Universidade Federal de Sergipe quanto a sua região de origem e sua inserção na comunidade acadêmica por tempo, tais quais os de Corrêa (2019), Ribeiro (2019) e Siqueira (2020). Os resultados obtidos demonstram que os falantes da amostra apresentam padrões linguísticos diferentes a depender de sua comunidade de origem.

Palavras-chave: Mobilidade. Contato. Mudança Linguística.

ABstract: Mobility has an important role on the mechanism of linguistic change in Brazilian Portuguese (BORTONI-RICARDO, 1985, 2011; OUSHIRO, 2016). Due to mobility, speakers come onto contact with linguistic variables that are not from their origin community, leading them to incorporate these variables in their repertoire and to disseminate them in other communities. In this paper, we aim to discuss studies related to mobility and language to understand how, from displacement and contact with different norms, speakers can change their linguistic behavior. We focus on studies based on the sample Deslocamentos (2019), from the Falares Sergipanos database (FREITAG, 2013), which considers the speech of university students at the Federal University of Sergipe regarding their region of origin and their insertion in the academic community in terms of time, such as Corrêa (2019), Ribeiro (2019) and Siqueira (2020). The results show that speakers of the sample present different patterns depending of their origin community.

KEYwords: Mobility. Contact. Linguistic Change.

\footnotetext{
"Mestre em Letras (Estudos Linguísticos) pelo programa de Pós-graduação em Letras (PPGL) da Universidade Federal de Sergipe (UFS). E-mail: manoel.siqueira77@hotmail.com. ORCID: https://orcid.org/0000-0002-5928-3450.
} 


\section{INTRODUÇÃo}

A realidade brasileira é amplamente marcada pela mobilidade. Desde o surgimento das metrópoles, das mudanças da capital brasileira ou dos ciclos econômicos, pessoas se deslocam (por movimentos pendulares, sazonais, de migração e imigração) para diferentes regiões do Brasil, atrás de emprego, de estudos, de melhor qualidade de vida etc. A mobilidade torna-se uma das características que definem a população brasileira, o que incide sobre a configuração da sociedade e, consequentemente, da língua, uma vez que suas realizações dependem dos contextos sociais, culturais e geográficos nos quais os indivíduos estão inseridos (LABOV, 2006).

A mobilidade apresenta importante papel sobre a mudança linguística no Brasil (cf. BORTONI-RICARDO, 1985, 2011; OUSHIRO, 2016; entre outros). Em função da mobilidade, falantes entram em contato com variáveis linguísticas que não fazem parte de sua comunidade de origem: o contato com essas variáveis leva-os a incorporá-las em seu repertório e/ou a difundir variáveis de sua comunidade de origem para a nova comunidade (BRITAIN, 2006, 2008).

Estudos linguísticos que têm evidenciado a influência da mobilidade como difusora de inovações linguísticas demonstram seu papel condicionador da variação e de mudança linguística (cf. BRITAIN, 2008; BORTONI-RICARDO, 2011). Labov (2008, p. 343) cita, por exemplo, o processo de migração do rural para o urbano em que, quanto ao falar do indivíduo rural, "mesmo sendo um marcador de identidade local, e uma fonte de prestígio em casa, ele [o falante rural] já pode ter consciência do caráter provinciano de sua fala antes de chegar na cidade". Decorrente disso, o falante altera a sua fala (conscientemente e inconscientemente) de acordo com as regras linguísticas de sua nova comunidade.

No Brasil, estudos pioneiros sobre a relação entre mobilidade e língua incluem os realizados por Bortoni-Ricardo (1985, 2011), que analisa como migrantes rurais se ajustam ao ambiente urbano. Focando-se principalmente em Brasília (DF), e na migração de brasileiros para residência na cidade satélite Brazlândia, a autora observa as mudanças linguísticas que ocorreram no repertório desses indivíduos, com enfoque em variáveis fonológicas (BORTONIRICARDO, 1985, 2011). Os resultados demonstram que quanto mais integrado à nova comunidade o falante for, maior será a tendência para que ele mude seu comportamento linguístico de tipicamente rural ou caipira para um comportamento linguístico mais urbano.

No escopo do projeto Como fala, lê e escreve o universitário?, na Universidade Federal de Sergipe (UFS), temos observado o comportamento linguístico dos falantes universitários em função de sua mobilidade, considerando a universidade como centro de deslocamentos e contatos, como também em função da integração do universitário. Os resultados das pesquisas vinculadas a esse projeto evidenciam a ação da mobilidade e do contato linguístico na fala dos estudantes (CORREA, 2019; RIBEIRO, 2019; SIQUEIRA, 2020): a depender da região do falante e de sua inserção na comunidade acadêmica, pode haver mudança no modo como ele faz uso da língua. 
A fim de contribuir para discussões acerca do tratamento da mobilidade em estudos linguísticos, neste texto, temos por objetivo apresentar e discutir estudos relacionados ao controle da mobilidade em variáveis linguísticas, de modo a compreender como, a partir do deslocamento e do contato com diferentes normas, o falante pode mudar seu comportamento linguístico. Tomamos como enfoque estudos feitos com base na amostra Deslocamentos (2019), do banco Falares Sergipanos (FREITAG, 2013), que considera a fala de universitários da UFS quanto a sua região de origem e a sua inserção na comunidade acadêmica em termos de tempo, tais quais os estudos de Corrêa (2019), Ribeiro (2019) e Siqueira (2020). Esperamos contribuir com discussões sobre o papel da mobilidade e do contato linguístico para a mudança linguística. As discussões que seguem ajudam-nos a compreender esse papel.

\section{Processos de MigraÇÃo e deslocamentos}

Para compreendermos a mobilidade, é preciso compreendermos o porquê de falantes migrarem. Lee (1980, p. 99) argumenta que "não se põem limitações com respeito à distância do deslocamento, ou à natureza voluntária ou involuntária do ato, como também não se estabelece distinção entre a migração externa e a migração interna". A migração teria como base o desenvolvimento econômico do indivíduo que, após analisar o custo-benefício de migrar, decide sobre o empreendimento de se deslocar (OLIVEIRA, 2011).

A migração é entendida como a mudança permanente ou semipermanente de residência do indivíduo (LEE, 1980). No Brasil, os últimos estudos feitos sobre a migração interna de forma permanente levam em consideração dados do Censo Demográfico 2000 (1995/2000) e da Pesquisa Nacional por Amostra de Domicílios - PNAD, realizada entre 2004 e 2009. O Censo 2000

mostrou que os deslocamentos entre as regiões brasileiras envolvem cerca de 3,3 milhões de pessoas, dentre as quais, entre entradas e saídas, destacou-se a Região Nordeste que apresentou a maior perda absoluta (760 mil pessoas), tendo as trocas com o Sudeste contribuído com cerca de $2 / 3$ dessa perda (OLIVEIRA et al., 2011, p. 30).

Um considerável contingente de pessoas tem migrado de suas localidades. A região Nordeste apresenta o maior número de evasão, com grande parte de seus migrantes indo para a região Sudeste do país. Dados do período entre 1999 e 2009 mostram que mais de 4,8 milhões de pessoas migraram entre regiões no Brasil, e só no Nordeste foram mais de 300.000 pessoas (OLIVEIRA et al., 2011). O estado de Sergipe, por exemplo, manteve uma estabilidade quanto à rotatividade de migração. Nos dados de 2004/2009, mais de 45.843 migraram para esse estado, advindos de diversas regiões do Brasil. 
A migração semipermanente, que envolve a mudança para uma nova área por um período de tempo limitado - e que aqui tomamos como enfoque -, ocorre por meio de dois movimentos: movimentos de circularidade e de pendularidade. O movimento de circularidade é entendido como "o movimento no qual a pessoa, sem ter mudado de residência, em um período de 30 dias, passe fora de casa a trabalho ou outras atividades" (OLIVEIRA, 2011, p. 17-18). Nesse movimento, o indivíduo reside em uma determinada cidade/região, mas precisa, sazonalmente, residir em uma outra localidade, por não poder fazer o percurso diário por conta da distância ou por questões financeiras. Tomemos como exemplo um estudante universitário que mora no interior do estado de Sergipe, e a universidade mais próxima se localiza a mais de $100 \mathrm{~km}$. O trajeto diário é inviabilizado por questões de tempo e questões financeiras. De modo a ter acesso à universidade, o universitário empreende um movimento de circularidade, residindo sazonalmente em áreas geográficas próximas ao centro de estudo.

O outro movimento, o de pendularidade, implica nas rotações diárias feitas pelo indivíduo de seu local de residência para seu local de trabalho ou estudo (OLIVEIRA, 2011): um operário que trabalha na cidade vizinha a sua precisa fazer um movimento pendular se quiser desenvolver suas atividades. Um estudante universitário que faz faculdade em uma cidade próxima também precisa se deslocar diariamente para ter acesso ao estudo. O que diferencia esses dois movimentos é o tempo longe de suas residências-base: enquanto um exige maior intervalo de tempo, o outro exige um menor.

A realidade brasileira apresenta em sua constituição populacional processos de migração. As comunidades são compostas por pessoas advindas de diferentes regiões do país culturalmente e linguisticamente plural-, movidas por alguma necessidade, socioeconômica ou não. Esses indivíduos integram novos grupos sociais e inserem-se como parte deles. Uma universidade, por exemplo, torna-se um centro de mobilidade, atraindo um amplo contingente populacional para ter acesso à educação. Universidades Federais, precisamente, atraem indivíduos de diferentes localidades. Na seção que segue, apresentamos como a Universidade Federal de Sergipe (UFS) se tornou um centro de mobilidade.

\section{A EXPANSÃo No ACESSO À UFS}

Para que a UFS se tornasse um centro de mobilidade, foi preciso que antes ela passasse por mudanças em relação ao seu acesso, principalmente políticas que permitissem o ingresso de pessoas de diversas camadas sociais. Tais mudanças começaram a ocorrer no início deste século, na primeira década, momento no qual o acesso à educação pública no Brasil foi marcado por crescente expansão. Com o advento de políticas públicas para a educação, diversos avanços foram feitos para que houvesse uma democratização no ensino, que

compreende reverter o quadro no qual ir à universidade é opção reservada às elites. A definição de um projeto para a educação superior deve 
entender esta como bem público, destinada a todos indistintamente, inserida no campo dos direitos sociais básicos, tratada como prioridade da sociedade brasileira, sendo que a universidade deve ser a expressão de uma sociedade democrática e multicultural, em que se cultiva a liberdade, a solidariedade e o respeito às diferenças (SESu, 2014, p. 19).

Idealizando fornecer um acesso democrático ao ensino superior no Brasil, metas foram traçadas, com a proposta de ter, nas universidades públicas, 30\% das pessoas com faixa etária entre 18 e 24 anos até o final da década de 2010. Com uma série de ações feitas, 9.306.877 pessoas concluíram o curso no período objetivado, o equivalente a 5\% da população brasileira em 2014 (SESu, 2014), apontando que as políticas públicas desenvolvidas estavam funcionando. Das políticas públicas relativas à democratização do ensino superior, citamos algumas no Quadro 1 .

Quadro 1 - Avanços 2003-2014

- Criação de 18 novas universidades federais;

- Criação de 173 campi de universidades federais em cidades do interior do país;

- Criação, em 2008, do Plano Nacional de Assistência Estudantil (Pnaes), para estudantes das universidades federais;

- Criação, em 2013, do Programa de Bolsa Permanência para estudantes das universidades federais;

- Aprovação, em 2012, e implantação, a partir de 2013, da Lei das Cotas nas universidades federais, com previsão de reserva de no mínimo 50\% das vagas, até 2016 , para estudantes oriundos das escolas públicas de ensino médio;

- Democratização do acesso à universidade, com o uso dos resultados do Exame Nacional do Ensino Médio (ENEM) nos processos seletivos.

Fonte: Secretaria de Educação Superior (2014, p. 27-28).

Essas políticas públicas levaram a uma maior inserção de pessoas de diversas camadas sociais e étnicas na educação superior gratuita no Brasil. A Universidade Federal de Sergipe (UFS) encontra-se nesse quadro, já que

a efetivação de políticas públicas como o REUNI e a mudança do processo de seleção (que antes era feito pela Fundação Carlos Chagas e atualmente se dá pelo SiSU, através do ENEM), bem como a Lei de Cotas, levou à ampliação no número de matrículas de estudantes que vêm de todo o estado de Sergipe e de muitos estados do Brasil (RIBEIRO, 2019, p. 21). ${ }^{1}$

${ }^{1}$ As discussões sobre as políticas de expansão do ensino superior e a democratização do acesso à Universidade Federal de Sergipe são um empreendimento em comum entre outras pesquisadoras, como Andrade (2017) e Corrêa (2019). 
Em um dos principais avanços em relação à UFS, podemos citar a interiorização (Figura 1), que permitiu que moradores do interior de Sergipe, e não apenas os da região metropolitana do estado, tivessem acesso à universidade perto de suas residências, visto que "os egressos do ensino médio sem opções de educação superior em sua região tendem a migrar, muitas vezes em caráter definitivo, para locais onde a oferta é mais ampla e diversificada" (SESu, 2014, p. 20), como muitos faziam em relação à sede da universidade.

Figura 1 - Campi da Universidade Federal de Sergipe

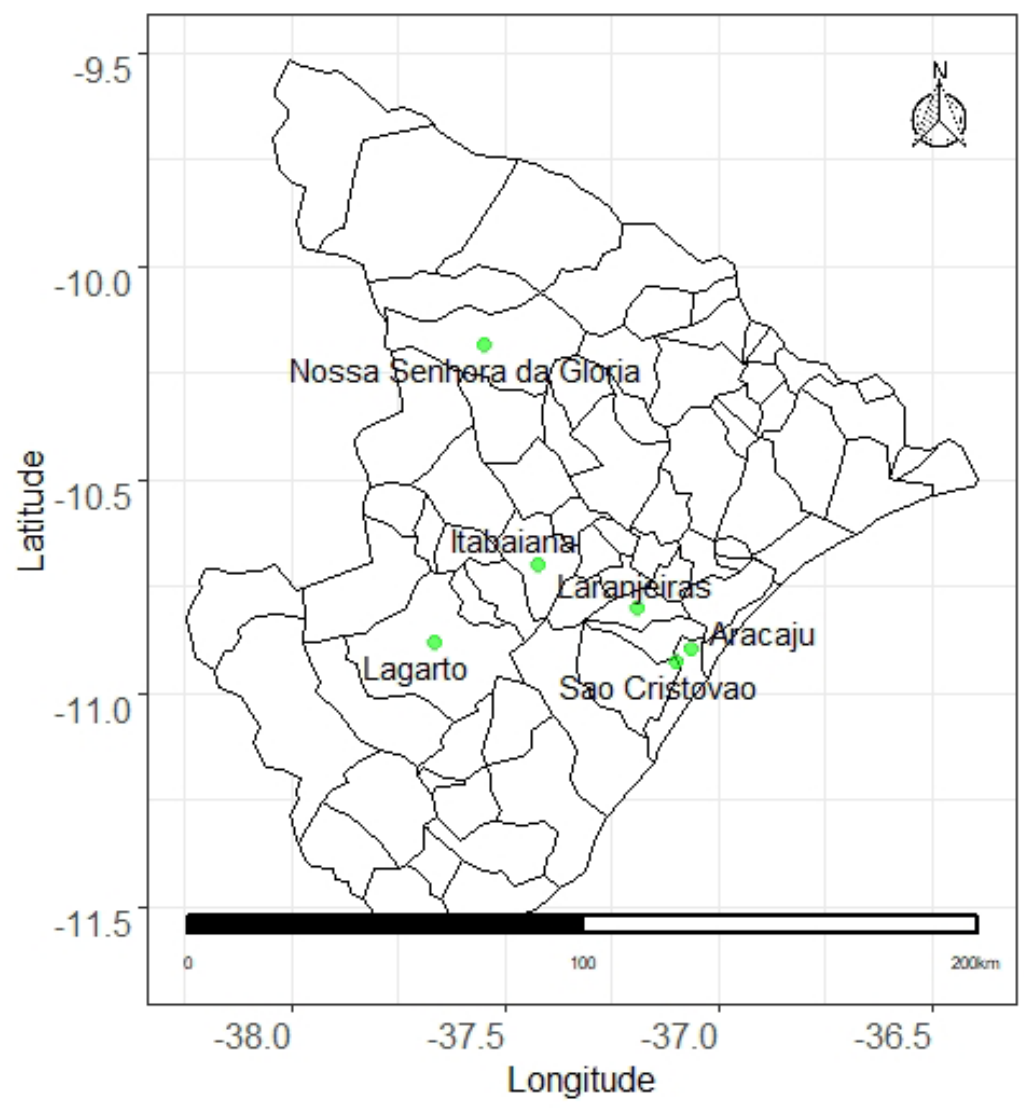

Fonte: elaboração própria.

A interiorização permitiu que a UFS saltasse de dois campi em 2006 (São Cristóvão e Aracaju), para um total de seis nos dias atuais (acrescidos os campi de Laranjeiras, Lagarto, Itabaiana e o Campus do Sertão, em Nossa Senhora da Glória). Os dados em relação ao número de matrículas no Nordeste, um aumento de $94 \%$, dão uma dimensão em relação aos resultados da interiorização, principalmente os ganhos desse programa, já que "a interiorização da oferta de educação superior é essencial para combater o desequilíbrio no desenvolvimento regional e atingir estudantes sem condições de se deslocar para outras regiões” (SESu, 2014, p. 20). 
Outro ponto a ser levado em consideração nesses avanços é o sistema de cotas ou lei de cotas (Lei $n^{\circ}$ 12.711/2012). Por meio dessa lei, homologou-se como obrigatória a reserva de metade das vagas ofertadas nas universidades para grupos "historicamente subrepresentados na educação superior" (SESu, 2014, p. 24). Nesses grupos, inserem-se negros, indígenas, pessoas com deficiência, egressos da educação pública e pessoas com renda mensal de até 1/2 salário mínimo per capita.

$O$ advento da lei de cotas, que busca reverter a ideia de que a universidade era reservada à elite, logo começou a obter resultados. Exemplo disso é a pesquisa do IBGE, feita em 2018, divulgada apenas em novembro de 2019 , que pontua que, das pessoas cursando universidades públicas no Brasil, 50,3\% delas são negras ou pardas, primeira vez na história do Brasil que a população negra alcança maior representação no ambiente $(\mathrm{Gl}, 2020)$.

Consideramos, ainda, os programas de apoio financeiro, como o Programa de Apoio ao Desenvolvimento da Aprendizagem Profissional (PRODAP) - uma concessão de bolsas destinadas à participação de estudantes da graduação presencial em atividades -, Bolsa Permanência - que concede auxílio financeiro a estudantes de origem indígena e quilombola e em situação de vulnerabilidade socioeconômica -, Auxílio Moradia e Residência Universitária - aquele com auxílio para custo de aluguel e este com alocação em moradia semelhante ao familiar, com até oito pessoas -, entre outros.

A implementação dessas políticas públicas, que resulta em um método mais acessível, ajudou a UFS a se tornar uma instituição que recebe uma variedade de estudantes pertencentes a diferentes classes sociais, etnias etc., que se deslocam para fazer parte do seu quadro universitário, interagem, e começam a desenvolver práticas em conjunto.

O campus Prof. José Aloísio de Campos da UFS é um exemplo dessas mudanças. Situado no Bairro Jardim Rosa Elze, São Cristóvão, o campus oferta, por ano, mais de 4000 vagas nos seus 78 cursos. Dos alunos que vão preencher essas vagas, há os que são oriundos da região do campus, como também os que moram em cidades circunvizinhas e fazem o movimento pendular diário. $\mathrm{O}$ campus ainda recebe alunos de áreas mais distantes que precisam migrar para ter acesso ao ensino, sejam alunos do interior de Sergipe, sejam alunos oriundos de outros estados.

Considerando que Sergipe é o menor estado do país e que faz divisa com Alagoas e Bahia, é de se assumir que uma parte dos estudantes seja desses estados, como também de outros. Esses alunos muitas vezes recorrem a morar nas redondezas da universidade, visto a facilidade de acesso tanto ao campus quanto ao Restaurante Universitário.

Pensando nisso, uma esquematização sobre a mobilidade desses estudantes foi montada no escopo do projeto Como fala, lê e escreve o universitário?, na Universidade Federal de Sergipe (UFS), sob orientação da prof. Dra. Raquel Freitag (Quadro 2). 
Quadro 2 - Deslocamentos

\begin{tabular}{|c|c|}
\hline Deslocamento 1 & $\begin{array}{c}\text { Estudantes da UFS nascidos na Grande Aracaju (Aracaju, Nossa Senhora } \\
\text { do Socorro, São Cristóvão e Barra do Coqueiros) e que residem nela. }\end{array}$ \\
\hline Deslocamento 2 & $\begin{array}{c}\text { Estudantes da UFS nascidos no interior de Sergipe que fazem o trajeto } \\
\text { diário para a UFS. }\end{array}$ \\
\hline Deslocamento 3 & $\begin{array}{c}\text { Estudantes da UFS nascidos no interior de Sergipe que residem na } \\
\text { Grande Aracaju. }\end{array}$ \\
\hline Deslocamento 4 & $\begin{array}{c}\text { Estudantes da UFS nascidos em outros estados, que atualmente residem } \\
\text { na Grande Aracaju. }\end{array}$ \\
\hline
\end{tabular}

Fonte: elaboração própria, a partir de Araújo et al. (2019).

Quatro formas de deslocamento, ou perfis de mobilidade, podem ser observadas. Os dois primeiros deslocamentos representam aqueles que, ao fim do dia, estão em suas residências originárias, já que o percurso para a universidade não é longo. Os outros dois deslocamentos abarcam alunos que migram para as redondezas da universidade durante o período em que estão estudando na UFS. Na terminologia migratória, os estudantes do Deslocamento $1 \mathrm{e}$ 2 representam o movimento pendular, visto o percurso diário, enquanto os do Deslocamento 3 fazem o movimento circular, retornando a suas casas originárias apenas após um maior período de tempo. Os estudantes do Deslocamento 4 também se inserem no movimento circular. Entretanto, seu tempo de retorno pode ser extremamente longo, dependendo de sua região de origem.

A região próxima à universidade torna-se uma área com expansão no fluxo de mobilidade, onde estudantes se deslocam para as regiões universitárias a fim de ter acesso ao ensino, ampliando a rotatividade no estado de Sergipe. Esse deslocamento, essa mobilidade, juntamente ao contato linguístico - aqui restringido ao processo pelo qual falantes de diferentes variedades de língua interagem entre si - com falantes advindos de diferentes comunidades resulta em mudanças no modo como o falante faz uso de sua língua, conforme vemos nas seções seguintes.

\section{Contato Linguístico}

Inovações linguísticas são, geralmente, difundidas geograficamente de uma área para outra (TRUDGILL, 1986). Formas linguísticas que não pertencem a uma comunidade podem ser inseridas nela por meio do contato. Ao migrar, o falante entra em contato com variedades linguísticas que não são a sua, difundindo e absorvendo novas variáveis. O contato linguístico é definido como o processo pelo qual falantes de diferentes línguas ou variedades interagem e, a partir dessa interação, há troca de formas linguísticas (TRUDGILL, 1986). 
Para Britain (2018, p. 143, tradução nossa), "até certo ponto, todas as interações entre falantes de um idioma representam casos de contato com o dialeto, pois o dialeto de todos é pelo menos sutilmente diferente do de todos os outros, mesmo na mesma comunidade, família ou grupo de colegas". Interagir com alguém implica a troca de formas linguísticas, mesmo que nem sempre adotadas por eles. No contato entre dialetos, "quando dois falantes de diferentes variedades da mesma língua que são completamente mutualmente inteligíveis entram em contato e conversam, itens podem ser transferidos de uma das variedades para a outra" (TRUDGILL, 1986, p. 1, tradução nossa). ${ }^{3}$ Os falantes adotam formas linguísticas diferentes, já que línguas - ou variedades - que estão socialmente em contato com outras mudam, como resultado de também estarem em contato fisiologicamente, na competência linguística do indivíduo.

No contato linguístico, as formas que os falantes inserem em seu repertório são os marcadores linguísticos da comunidade (TRUDGILL, 1986). Estando ao nível de consciência social, e sendo uma forma característica da fala da comunidade, o falante muda a sua fala, de forma inconsciente, como modo de aceitação nessa nova comunidade. Isso porque os falantes são mais conscientes de formas vistas como marcadores do que aquelas formas vistas como indicadores - que estão abaixo do nível de consciência social e não envolvem variação estilística, como também são mais suscetíveis a adotarem marcadores do que estereótipos - formas com alto nível de consciência social que podem possuir julgamentos negativos (CHAMBERS; TRUDGILL, 2004).

A discussão, então, recai sobre o nível de consciência social e estilística da variante na comunidade: falantes adotam os marcadores como modo de aceitação na comunidade por serem formas linguísticas perceptíveis e que não sofrem estigma. Dessa forma, podem evitar julgamentos sociais e linguísticos por parte da comunidade na qual eles querem ser vistos como pertencentes.

No caso de um marcador dialetal - aqui entendido como uma variável linguística com distinção geográfica -, a integração do falante em uma nova comunidade faz com que ele, inconscientemente, adote um novo comportamento, como modo de pertencimento ao novo grupo. A incorporação de novas formas linguísticas pode levar a mudanças no modo como os falantes fazem uso de sua língua.

Na Universidade Federal de Sergipe, em que há a presença de alunos de outros estados - como também alunos de diferentes faixas etárias, escolaridades e sexo/gênero - é presumível que haja o contato linguístico e a troca de formas linguísticas, como também é presumível que a norma acadêmica altere o falar do aluno, visto a busca por aceitação em seu novo ambiente, já que

\footnotetext{
2 "to a certain extent, all interactions between speakers of a language represent cases of dialect contact, since everyone's dialect is at least subtly different to everyone else's even within the same community, family, or peer group (BRITAIN, 2018, p. 143)".

3 "when two speakers of different varieties of the same language which are completely intelligible come into contact and converse, items may be transferred from one of the varieties to the other (TRUDGILL, 1986, p. 1)".
} 
a universidade é uma experiência de realocação comum, embora não universal, para jovens adultos, muitas vezes envolvendo movimentos para novas regiões dialetais, ou interação com outros que vieram de outras regiões. Além disso, estudantes universitários passam por desenvolvimento significativo e mudança de identidade social (Arnett 2000, Larose e Boivin 1998), o que permite investigar os efeitos concorrentes ou cooperativos de exposição e identidade na mudança da língua (CAMPBELL-KIBLER et al., 2014, p. 21, tradução nossa). ${ }^{4}$

A integração desses estudantes em novos grupos sociais universitários atua como condicionante na constituição de sua língua, uma vez que amplia o contato do aluno com diferentes variedades. Com formas linguísticas sendo adotadas na interação, o repertório de todos os participantes contém variáveis linguísticas que não são características de sua comunidade de fala de origem, já que línguas ou variedades que estão em contato podem ser linguisticamente alteradas (TRUDGILL, 1986), levando com que o falante oriundo de outra região adote traços de sua nova comunidade.

A inserção do indivíduo na comunidade influencia seus usos linguísticos. O contato entre normas, ocasionado pela migração, pode gerar uma acomodação do indivíduo ao seu novo grupo, o que buscamos discutir neste trabalho.

\section{Conjunto de dados E MÉTOdo}

As pesquisas que apresentamos e discutimos aqui foram desenvolvidas com base na amostra Deslocamentos (2019), pertencente ao banco de dados Falares Sergipanos (FREITAG, 2013), composta por dados orais de falantes universitários da UFS, campus Prof. José Aloísio de Campos, São Cristóvão, SE. As entrevistas que compõem a amostra foram guiadas por um roteiro contendo questões que englobam relatos de experiências e opiniões acerca de assuntos sociais, como educação, saúde, gênero etc.

A amostra é composta por 64 informantes, estratificados segundo deslocamentos (cf. Quadro 2), tempo no curso (do $3^{\circ}$ período para baixo - início - e do $7^{\circ}$ período para cima - final) e gênero do informante (masculino ou feminino), conforme Quadro 3.

\footnotetext{
4 "college is a common, though by no means universal, relocation experience for young adults, often involving moves to new dialect regions, or interaction with others who have come from other regions. In addition, college students undergo significant development and change of social identity (Arnett 2000, Larose and Boivin 1998), allowing us to probe the competing or cooperative effects of exposure and identity in language change (CAMPBELL-KIBLER, 2014, p. 21)”.
} 
Quadro 3 - Estratificação da amostra

\begin{tabular}{|c|c|c|c|c|}
\hline & \multicolumn{2}{|c|}{ Início } & \multicolumn{2}{c|}{ Final } \\
\cline { 2 - 5 } & Masculino & Feminino & Masculino & Feminino \\
\hline Deslocamento 1 & 4 & 4 & 4 & 4 \\
\hline Deslocamento 2 & 4 & 4 & 4 & 4 \\
\hline Deslocamento 3 & 4 & 4 & 4 & 4 \\
\hline Deslocamento 4 & 4 & 4 & 4 & 4 \\
\hline
\end{tabular}

Fonte: elaboração própria.

Para análise dos dados, usamos a estatística descritiva e a inferencial, permitindo-nos observar as frequências e inferir se há associação entre as variáveis independentes (deslocamento e tempo no curso) e a variável dependente (o fenômeno descrito em cada estudo), além de dar respaldo a generalizações. Para a associação, realizamos testes de qui-quadrado, para observar se a frequência obtida é efeito do acaso ou se há interferência da variável independente. O teste de qui-quadrado nos dá um p-valor, que é comparado com o nosso p-valor pré-estabelecido, o $\alpha$ de 0.05 . Um p-valor igual ou maior que 0.05 demonstra que a frequência é efeito do acaso, não havendo interferência da variável independente; um p-valor abaixo de 0.05 demonstra que há associação significativa entre a distribuição da variável dependente e a variável independente. Para medir a força de associação, trabalhamos com o $V^{2}$ de Cramer, medida de associação que vai de o a 1, em que o representa a ausência de associação e 1 o nível mais alto.

As figuras apresentadas na seção seguinte foram feitas por meio da plataforma $R$ ( $R$ CORE TEAM, 2018), na interface RStudio, com suporte do pacote estatístico ggstatsplot (PATIL; POWELL, 2018), que já apresenta a frequência dos dados e os resultados dos testes estatísticos.

\section{DIFERENÇAS E MUDANÇAS EM FAVOR DA MOBILIDADE}

Nesta seção, apresentamos e discutimos os resultados dos estudos que consideram a mobilidade feitos com base na amostra Deslocamentos (2019), tais quais os de Corrêa (2019), Ribeiro (2019) e Siqueira (2020). Focamo-nos na apresentação e na discussão apenas das variáveis que dialogam com a mobilidade e com o contato linguístico: deslocamento e tempo no curso.

\section{A PALATAlizaÇÃo DAS OCLUSIVAS ALVEOLARES /T/ E /D/}

No português brasileiro, as ocorrências das consoantes / $t / \mathrm{e} / \mathrm{d} /$ variam em ambiente fônico regressivo, como nas pronúncias de /tia/ e /dia/, podendo haver a realização oclusiva, 
em [tia] e [dia], ou a realização palatal, em [tia] e [dzia]..$^{5}$ Os estudos realizados com base no português falado em Sergipe (SOUZA NETO, 2014; SOUZA, 2016) apontam que a realização palatal das consoantes / $\mathrm{t}$ / e /d/ é mais frequente "na fala dos falantes mais jovens, com maior nível de escolarização, e mais adiantado na capital do estado (FREITAG, 2016), o que sugere que a comunidade está passando por um processo de mudança” (CORREA, 2019, p. 14).

Centrada na comunidade de universitários da UFS, Corrêa (2019) descreve as realizações dessas consoantes questionando se o tempo de inserção dos estudantes universitários que compõem a amostra (e a consequente integração do estudante) influencia a frequência de uso das realizações de / $\mathrm{t} / \mathrm{e} / \mathrm{d} /$. Na distribuição geral dos dados, a autora observa um total de 12.800 ocorrências das consoantes. Dessas ocorrências, 9.396 (73\%) correspondem a realização oclusiva [tia], enquanto 3.404 (27\%) correspondem a realização palatal [ţia] (Figura 2).

Figura 2 - Distribuição de frequências das consoantes /t/ e /d/ em Corrêa (2019)

$$
\chi_{\text {gof }}^{2}(1)=2805.00, p=0 \mathrm{e}+00, \widehat{V}_{\text {Cramer }}=0.47, \mathrm{Cl}_{95 \%}[0.45,0.49], n_{\text {obs }}=12800
$$

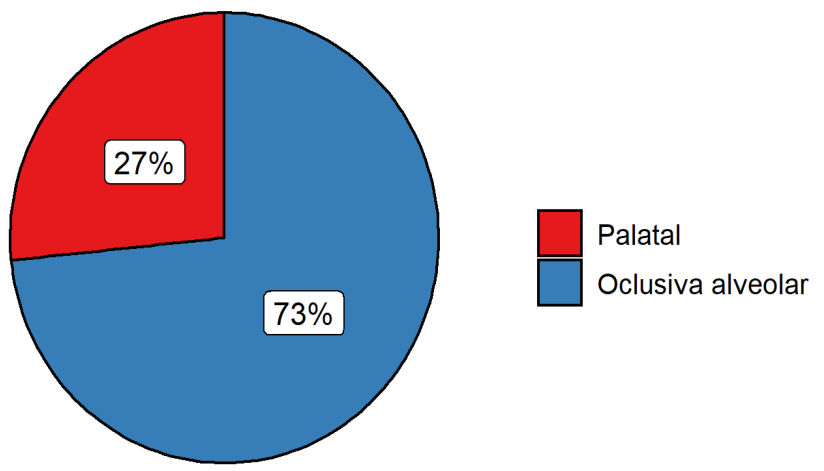

$$
\log _{\mathrm{e}}\left(\mathrm{BF} \mathrm{F}_{01}\right)=-\operatorname{Inf}, a_{\text {Gunel-Dickey }}=1.00
$$

Fonte: elaboração própria a partir de Corrêa (2019, p. 80).

Nos dados da amostra Deslocamentos (2019), há predomínio da realização oclusiva, como [tia] e [dia], o que segue a tendência de estudos anteriores (SOUZA, 2016; SOUZA NETO, 2014). Controlando o deslocamento dos informantes, com base na estratificação da amostra, a autora observa os dados apresentados na Figura 3.

\footnotetext{
${ }^{5}$ Aqui estamos adotando apenas a visão discreta binária (ou oclusiva ou palatal), mesmo havendo um gradiente entre ambas realizações.
} 
Figura 3 - Realização das consoantes /t/ e /d/ por deslocamento

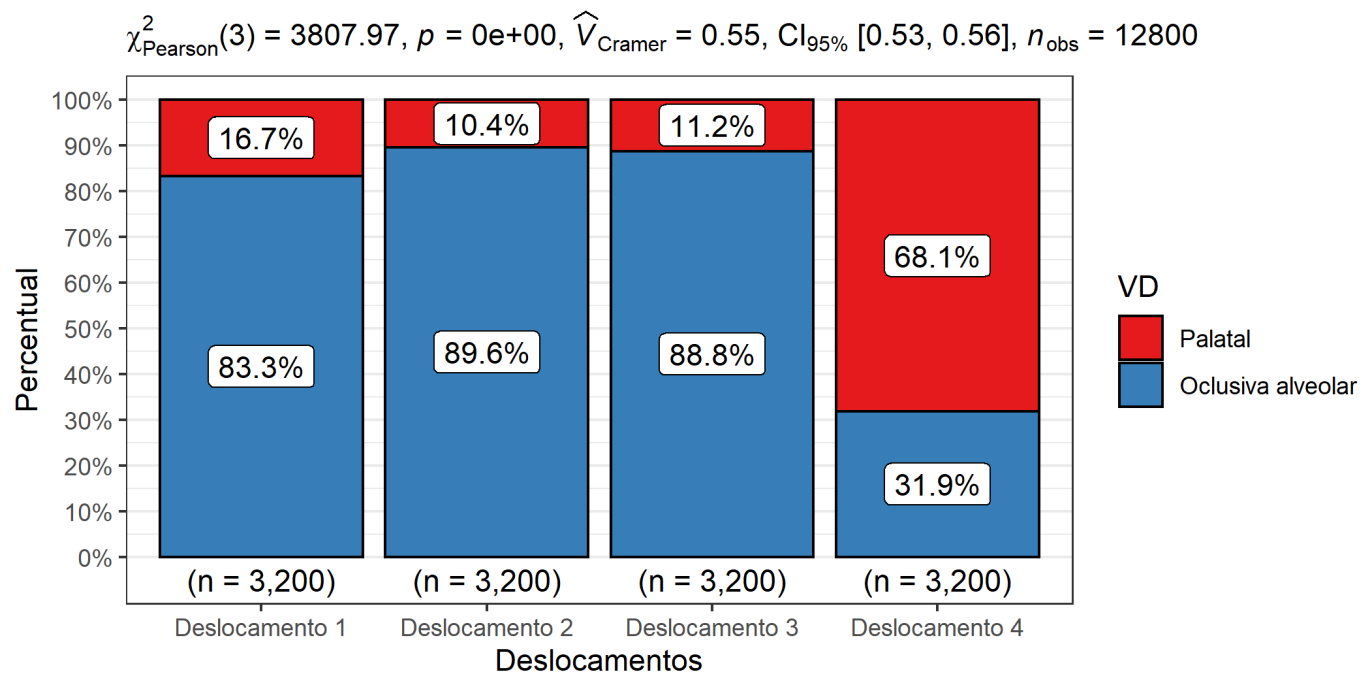

Fonte: elaboração própria a partir de Corrêa (2019, p. 92).

A frequência da realização palatal é maior com falantes do Deslocamento 4 (68,1\% 2180/3200), naturais de regiões externas a Sergipe e que se mudaram para a região metropolitana do estado para ter acesso à universidade. ${ }^{6}$ Falantes internos ao estado apresentam predomínio da variante oclusiva. A maior frequência da realização palatal entre os falantes do estado é observada com falantes do Deslocamento 1 (16,7\% 533/3200), residentes da região metropolitana do estado que podem ter mais contato com falantes externos, visto residirem em ambiente de amplo fluxo de turistas; seguido por falantes do Deslocamento 3 (11,2\% 359/3200), oriundos do interior do estado que se mudaram para a região metropolitana; e, por fim, falantes do Deslocamento $2(10,4 \% 332 / 3200)$, oriundos do interior do estado que fazem o percurso diário para o campus. A diferença existente entre os dados é estatisticamente significativa ( $X^{2}(3$, $N=12.800)=3807.97, p<0.001)$, com associação média $\left(\mathrm{V}^{2}=0.55\right)$.

É na fala de falantes externos ao estado que há predomínio da realização palatal. Com falantes naturais do estado, embora haja ocorrências da realização palatal, predomina a realização oclusiva:

Podemos verificar que os deslocamentos geográficos apresentaram valores de frequências bastante diversificados entre um e outro, o que indica que o fator geográfico/dialetal exerce influência no processo de variação e mudança quanto ao uso da variante palatal (CORREA, 2019, p. 95).

\footnotetext{
${ }^{6}$ Os falantes do Deslocamento 4 são, majoritariamente, oriundos da Bahia e de São Paulo, regiões em que há predomínio da variante palatal, o segundo com mais frequência.
} 
O controle da mobilidade no estudo de Corrêa (2019) demonstra que há diferenças nas realizações das consoantes / $\mathrm{t} / \mathrm{e} / \mathrm{d} /$ por deslocamento, o que evidencia uma polaridade entre a língua falada por naturais do estado, de um lado, e a língua falada por externos ao estado, do outro. Podemos observar a distribuição por tempo no curso, de modo a inferir se há mudanças com base em tempo aparente (Figura 4).

Figura 4 - Frequência das consoantes /t/ e /d/ por Tempo no curso

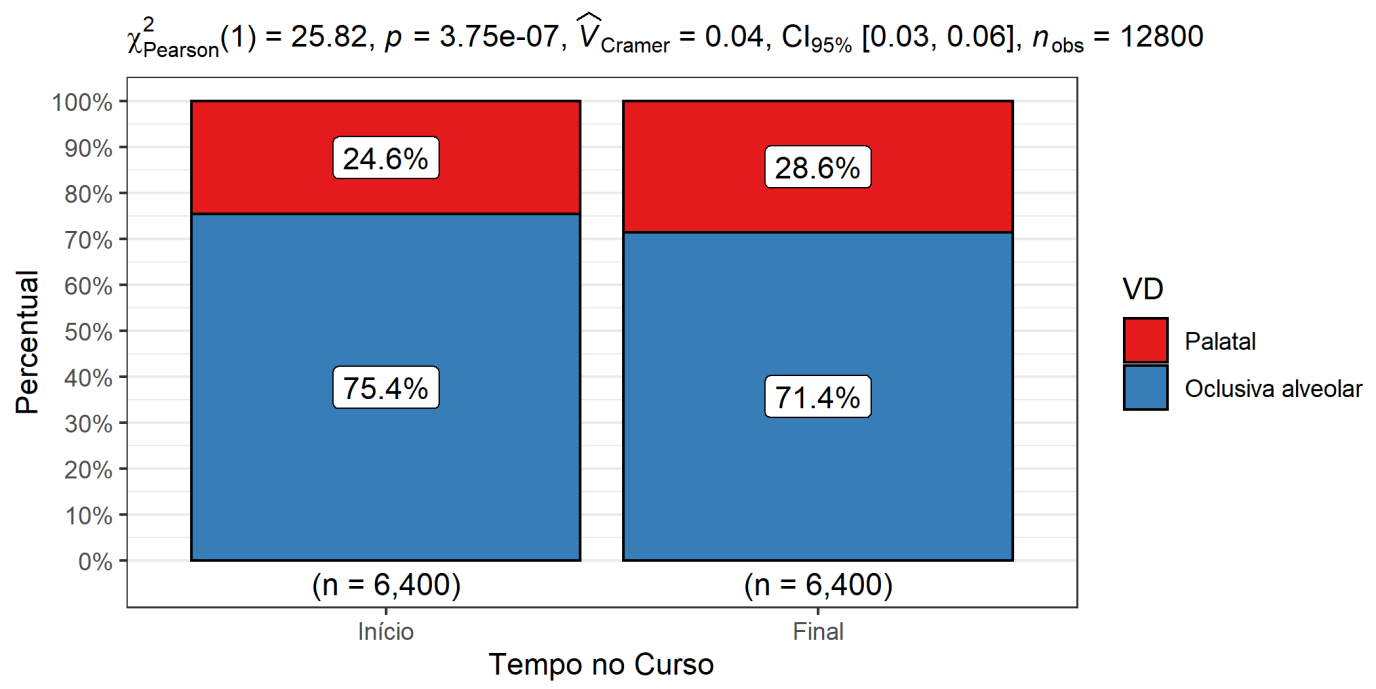

Fonte: elaboração própria a partir de Corrêa (2019, p. 91).

A frequência da realização palatal é maior na fala de universitários do final do curso (28,6\% 1829/6400), do que na fala de falantes do início do curso (24,6\% 1575/6400), e essa diferença é estatisticamente significativa $\left(X^{2}(1, N=12800)=25.82, p<0.001\right)$, com associação fraca $\left(V^{2}=0.04\right)$, o que nos leva a inferir que a inserção na comunidade por vias de tempo exerce influência nos usos da realização palatal. Para Corrêa (2019, p. 99), "os resultados apresentados mostram que dos quatro deslocamentos analisados nessa amostra, apenas o deslocamento III não apresentou aumento da variante palatal em relação ao fator final de curso". O aumento do uso ao final do curso pode ser um indício de uma mudança nos usos pelos falantes.

A mobilidade interfere na variação dos usos das consoantes / $t /$ e /d/ na comunidade universitária da UFS, além de que o tempo no curso apresenta indícios relativos à mudança no modo como esses falantes fazem o uso da língua. Na seguinte seção, vemos resultados do estudo de Ribeiro (2019). 


\section{AS PREPOSIÇÕES LOCATIVAS EM E NI}

No português brasileiro, há variação entre as preposições locativas em e ni: ambas as formas localizam o sintagma nominal no espaço, como em estou em Sergipe estou ni Sergipe. "A variante ni é comum na fala espontânea do brasileiro, principalmente em contextos mais rurais e de menos contato com bens de cultura letrada" (RIBEIRO, 2019, p. 13). Com isso, espera-se que seu uso seja restrito a ambientes informais, ligado ao costume regional, mais rural, à medida em que seu uso em centros urbanos e em ambientes formais seja restrito ou inexistente.

Ribeiro (2019) objetiva, em seu estudo, com base na amostra Deslocamentos (2019), descrever o padrão de recorrência da variação entre as preposições locativas em e ni em função do deslocamento geográfico dos estudantes, já que no deslocamento para regiões mais urbanizadas, falantes levam consigo traços linguísticos de sua comunidade de origem (RIBEIRO, 2019). Notemos, contudo, que a autora considera descrever apenas os padrões geográficos de deslocamento, sem observar os efeitos de integração à universidade por vias de tempo. Os resultados podem ser visualizados na Figura 5.

Figura 5 - Distribuição geral de $e m$ e $n i$

$$
\chi_{\text {gof }}^{2}(1)=2538.90, p=0 \mathrm{e}+00, \widehat{V}_{\text {Cramer }}=0.91, \mathrm{Cl}_{95 \%}[0.88,0.95], n_{\text {obs }}=3044
$$

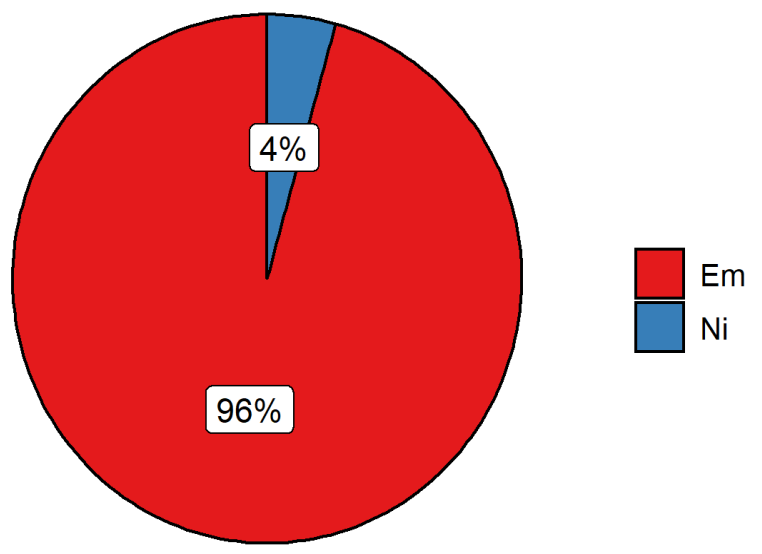

Fonte: elaboração própria a partir de Ribeiro (2019, p. 52).

Na amostra Deslocamentos (2019), foram obtidas 3044 ocorrências do contexto da variação. Dessas ocorrências, 132 (4\%) são para a variante ni. Há predomínio da variante $\mathrm{em}$ (96\%, 2912/3044), considerada mais urbana e padrão, uma vez que a variante rural e não padrão ocorre pouco na língua falada por universitários da UFS. Para Ribeiro (2019, p. 52),

estudantes de diferentes regiões com mobilidade geográficas distintas estão constantemente inseridos em contexto profissional (a 
universidade) e pessoal (em casa) e precisam realinhar seu código linguístico regularmente, estes entram em contato e compartilham variedades, a forma ni estaria presente nessas variedades e ocorreria no ambiente universitário.

Com base nisso, observamos o comportamento dos estudantes que compõem a amostra, considerando sua mobilidade, o seu deslocamento para a universidade, com vistas a descrever se há diferenças quanto à região de origem do universitário (Figura 6).

Figura 6 - Distribuição de em e ni por Deslocamento

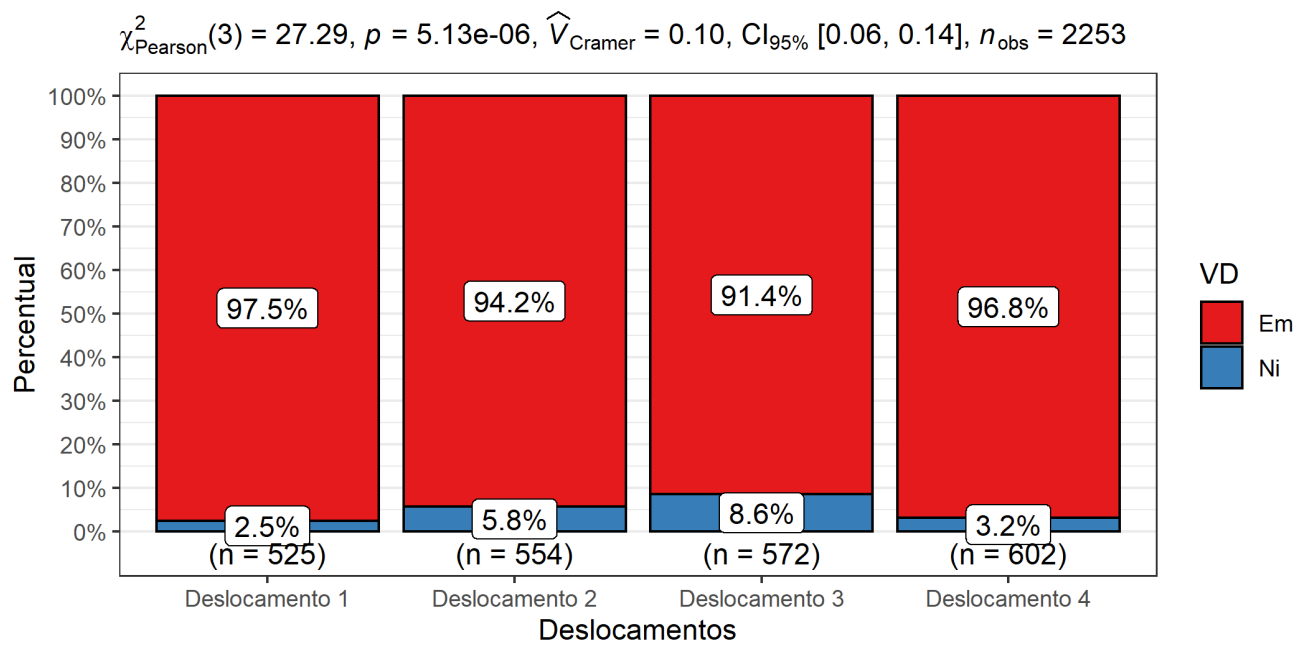

Fonte: elaboração própria a partir de Ribeiro (2019, p. 53).

A frequência da variante ni é maior com universitários do Deslocamento 3 (8,6\%, 49/572), do interior do estado, no qual há predomínio de ambientes rurais, e que se mudaram para a região metropolitana do estado para ter acesso à universidade. A segunda maior frequência é observada em universitários do Deslocamento 2 (5,8\%, 32/554), também do interior do estado, mas que fazem o movimento pendular de acesso à universidade. O Deslocamento 1 (2,5\%, 13/525), formado por universitários naturais e residentes da região metropolitana do estado, e o Deslocamento 4 (3,2\%, 19/602), formado por universitários externos ao estado de Sergipe, mas que se mudaram para a região metropolitana, são os deslocamentos que apresentam as menores frequências. A diferença existente entre os dados dos deslocamentos é estatisticamente significativa $\left(X^{2}(3, N=2253)=27.29, p<0.001\right)$, com associação fraca $\left(V^{2}=0.10\right)$.

Embora a variante ni ocorra em todos os deslocamentos, o predomínio se dá nos que os falantes provêm do interior do estado. São eles que tendem a usar a preposição ni, resultante de sua origem interiorana, o que indicaria um efeito da mobilidade (RIBEIRO, 2019). Ainda assim, há uma "regularidade no uso pelos falantes dos quatro tipos de deslocamento, com sutil recorrência nos deslocamentos do interior do estado" (RIBEIRO, 2019, p. 54). 
Até então, vimos variáveis que se relacionam com aspectos fonológicos: a variação na realização das consoantes / $\mathrm{t}$ / e /d/ está ao nível fonético-fonológico, a variação nas preposições locativas em e ni está ao nível morfofonológico. Variáveis nesses níveis são mais perceptíveis e mais representativas de diferentes dialetos da língua, sendo mais suscetíveis a apresentar diferenças quanto aos deslocamentos e a sofrer mudanças. O mesmo, possivelmente, não ocorre quando falamos de variáveis nos níveis gramaticais mais altos. Na seguinte seção, observamos o estudo de Siqueira (2020), que toma como enfoque uma variável morfossintática.

\section{A PRESENÇA DE ARTIGO DEFINIDO ANTES DE POSSESSIVOS}

No português brasileiro, os pronomes possessivos que antecedem nomes, como em sua mãe e nossa escola, podem (ou não) vir antecedidos por artigo definido, em a nossa casa e nossa casa. Estudos prévios com base no português brasileiro têm demonstrado que essa variação apresenta diferentes padrões de uso em diferentes comunidades, predominando a presença do artigo no português falado nas regiões Sul e Sudeste, e ausência no português da região Nordeste (cf. CALLOU; SILVA, 1997; LUCCHESI, 1993; GUEDES, 2019; SIQUEIRA, 2020).

Considerando esses padrões dialetais, Siqueira (2020) conduz seu estudo focando em aspectos de mobilidade e o contato entre variedades para descrever as realizações da variação na presença do artigo definido antecedendo possessivos, questionado se o contato linguístico entre normas e o deslocamento geográfico influenciam a realização da variável.

Em seus resultados, o autor obteve um total de 1268 ocorrências de possessivos que antecedem nomes. Dessas ocorrências, 699 (53\%) são para a ausência de artigo, enquanto 599 (47\%) são para a presença (Figura 7).

Figura 7 - Distribuição da presença/ausência de artigos definidos

$$
\chi_{\text {gof }}^{2}(1)=3.86, p=0.049, \widehat{V}_{\text {Cramer }}=0.05, C_{95 \%}[0.00,0.10], n_{\text {obs }}=1268
$$

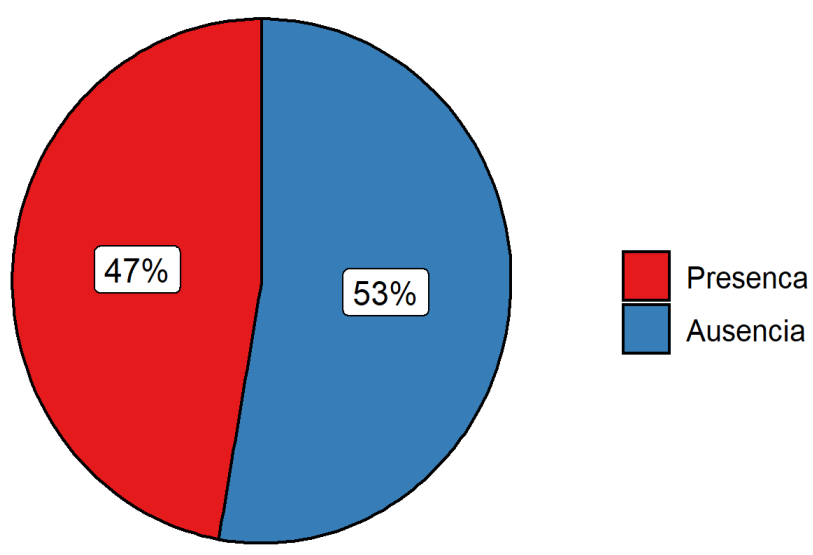

Fonte: elaboração própria a partir de Siqueira (2020, p. 20). 
Na amostra Deslocamentos (2019), há predomínio da ausência de artigo definido antecedendo possessivos pré-nominais, o que dialoga com resultados de pesquisas com enfoque em regiões do Nordeste (GUEDES, 2019). Contudo, relembramos que a amostra não conta apenas com a fala de falantes de uma única comunidade, mas de várias, com organizações culturais e geográficas diferentes, o que nos leva a observar o comportamento da variação com base na mobilidade (Figura 8).

Figura 8 - Realização da presença/ausência do artigo por Deslocamento

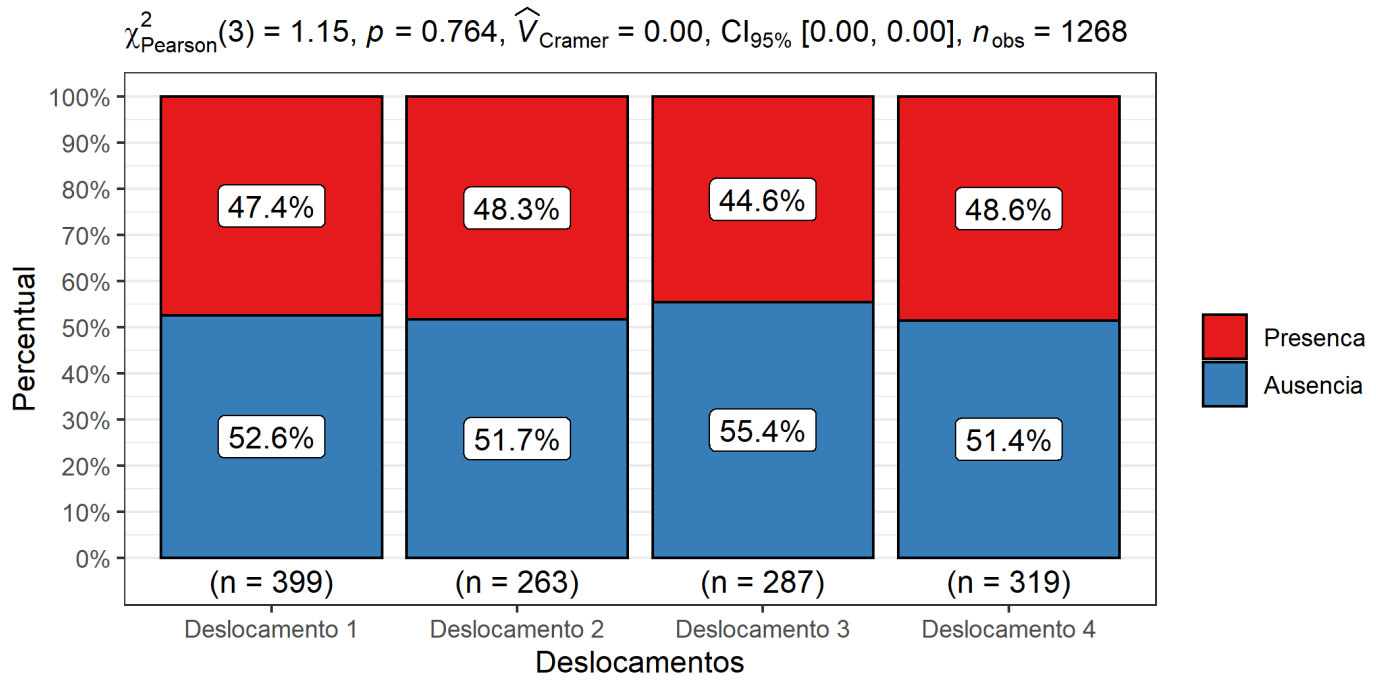

Fonte: elaboração própria a partir de Siqueira (2020, p. 27).

A frequência da presença é maior com falantes do Deslocamento 4 (48,6\%, 155/319), externos ao estado de Sergipe, seguido por falantes do Deslocamento 2 (48,3\%, 127/263), advindos do interior do estado que fazem o movimento pendular para a UFS, falantes do Deslocamento 1 (47,4\%, 189/399), oriundos da região metropolitana do estado que fazem o movimento pendular para a UFS, e, com a menor frequência, falantes do Deslocamento 3 (44,6\%, 128/287), do interior do estado que fazem o movimento circular, residindo na região metropolitana do estado.

Para Siqueira (2020, p. 27), "são os falantes externos ao estado de Sergipe que apresentam o maior índice de realização do artigo. Esse comportamento pode ser justificado pela região de origem dos falantes". Contudo, a diferença entre os deslocamentos não é significativa $\left(X^{2}(3, N=1268)=1.15, p=0.764\right)$, o que não nos permite inferir se, de fato, há interferência dos deslocamentos sobre a distribuição. Podemos, todavia, observar se há associação com o tempo no curso (Figura 9). 
Figura 9 - Realização da presença/ausência de artigo por Tempo no Curso

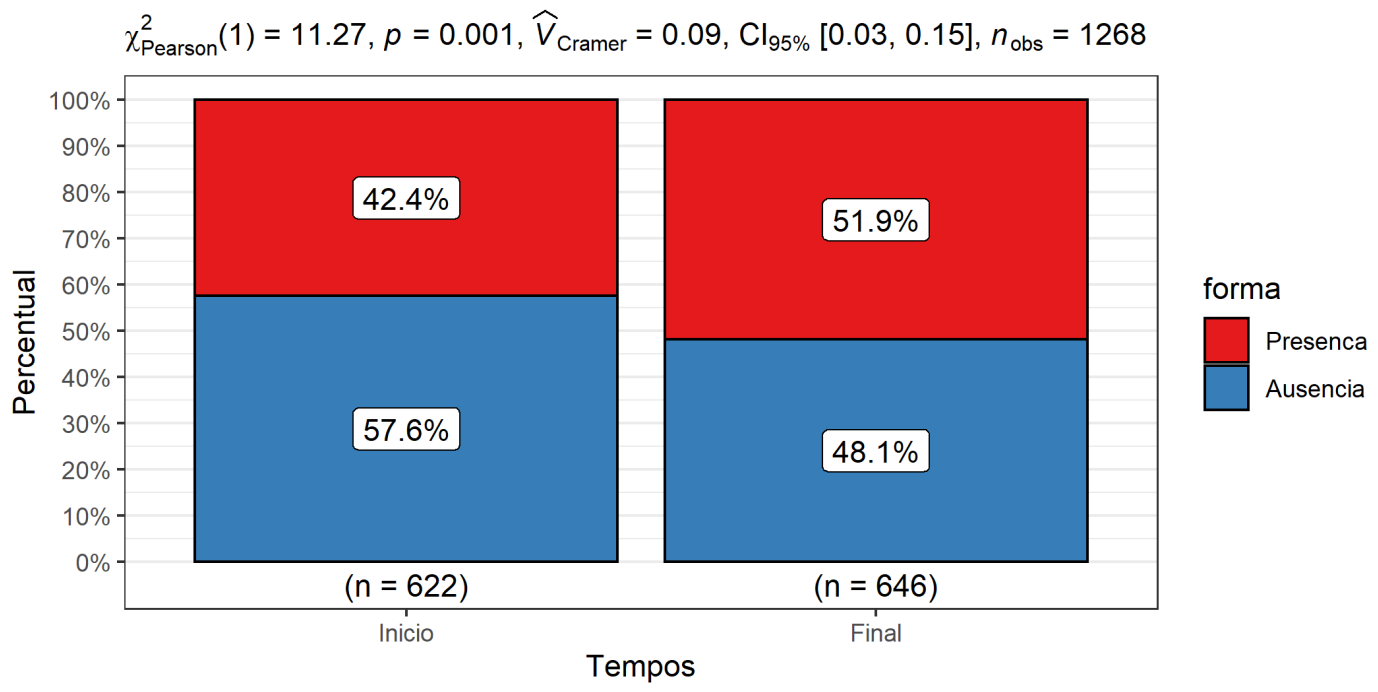

Fonte: elaboração própria a partir de Siqueira (2020, p. 28).

A frequência da presença de artigo antecedendo possessivos pré-nominais é maior com falantes do final do curso $(51,9 \%, 335 / 646)$, do que com falantes do início do curso $(42,4 \%$, 264/622), e essa diferença é estatisticamente significativa $\left(X^{2}(1, N=1268)=11.27, p<0.001\right)$. Há efeito do tempo no curso na distribuição do fenômeno, mas esse efeito é fraco $\left(\mathrm{V}^{2}=0.09\right)$. Para Siqueira (2020, p. 28),

os resultados indicam que esses alunos aumentam o uso do artigo na medida em que avançam na universidade [...]. Associamos esse comportamento ao engajamento do aluno durante o seu período de estudos com outros alunos com comportamentos linguísticos diferentes.

O maior engajamento dos falantes que compõem a amostra, juntamente ao contato com diferentes variedades do português, pode ter incidido sobre as realizações da variável na língua, resultando em mudança no modo como eles fazem usos da variação na presença de artigo definido antes de possessivos pré-nominais. Mesmo sendo uma variável morfossintática, as mudanças entre os tempos pode ser um indício de que essa variável já se encontra, em algum nível, presente na consciência do falante.

\section{CONSIDERAÇõES FINAIS}

Neste trabalho, tomamos como objetivo apresentar e discutir o efeito da mobilidade em usos linguísticos, de modo a compreender como, a partir do deslocamento e do contato com diferentes normas, o falante pode mudar seu comportamento linguístico. Usamos como base 
estudos desenvolvidos com dados de fala da amostra Deslocamentos (2019), do banco Falares Sergipanos (FREITAG, 2013), que considera a fala de universitários quanto ao seu acesso à universidade - em termos de mobilidade - e a sua integração - em vias de tempo.

Os resultados apresentados demonstram que os falantes apresentam padrões linguísticos diferentes a depender de sua comunidade de origem: universitários naturais de outros estados tendem a palatalizar mais do que os naturais de Sergipe (CORREA, 2019) - como nas pronúncias de /tia/ e /dia/ - e a realizar mais a presença de artigo antes de possessivos pré-nominais (mesmo a variável não sendo estatisticamente significativa) (SIQUEIRA, 2020) - como em a sua mãe; universitários do interior do estado usam mais a variante ni (oposta a em) do que estudantes da região metropolitana do estado (RIBEIRO, 2019) - como estudei ni escola pública.

Além disso, observamos que os falantes da amostra tendem a mudar seu comportamento linguístico com base nas normas de sua nova comunidade (CORREA, 2019; SIQUEIRA, 2020). Quanto maior o grau de inserção na comunidade, maior o grau de mudanças em sua língua, advinda tanto do contato linguístico quanto do engajamento desses estudantes em sua nova comunidade, ampla em diversidade social e linguística, a UFS. Com base nisso, pudemos compreender que a mobilidade e a inserção em uma nova comunidade podem interferir nos usos linguísticos feitos pelos falantes.

\section{Agradecimentos}

Agradecemos a Thaís Correa e a Cristiane Ribeiro pela condução de suas pesquisas e disponibilização dos dados. Agradecemos também à profa. Dra. Raquel Freitag (UFS) pelas orientações e pela coordenação do projeto no qual todas as pesquisas aqui revisadas foram desenvolvidas.

\section{REFERÊNCIAS}

ANDRADE, S. R. J. A expansão no acesso à educação superior no Brasil e a presença do novo aluno nas instituições de ensino superior. In: Anais do $10^{\circ}$ Encontro Internacional de Formação de Professores, Aracaju, 2017.

ARAUJO, A. S. et al. O controle da mobilidade na constituição de amostras sociolinguísticas. In: ABRALIN 50, 2019, Maceió (Apresentação de Trabalho/Comunicação).

BORTONI-RICARDO, S. M. The Urbanization of Rural Dialect Speakers: a Sociolinguistic Study in Brazil. Cambridge: Cambridge University Press, 1985.

BORTONI-RICARDO, S. M. Do campo para a cidade: estudo sociolinguístico de migração e redes sociais. São Paulo: Parábola, 2011. 
BRASIL. Ministério da Educação. Secretaria de Educação Superior. A democratização e expansão da educação superior no país 2003 - 2014. Brasília, 2014.

BRITAIN, D. Language/dialect contact. In: BROWN, K. (Ed.). Encyclopedia of Language and Linguistics. Elsevier, p. 651-657, 2006.

BRITAIN, D. Space, diffusion and mobility. In: CHAMBERS, J. K.; TRUDGILL, P.; SCHILLINGESTES, N. (Eds.). The handbook oflanguage variation and change. Blackwell publishing, p. 604-637, 2008.

CALLOU, D.; SILVA, G. M. O. O uso de artigo definido em contextos específicos. In: HORA, D. (Org.) Diversidade Linguística no Brasil. João Pessoa: Ideia, 1997.

CORREA, T. R. A. A variação na realização de /t/e /d/ na comunidade de práticas da UFS: mobilidade e integração. 121f. Dissertação (Mestrado em Estudos Linguísticos) - Universidade Federal de Sergipe, 2019.

FREITAG, R. M. K. Banco de dados Falares Sergipanos. Working Papers em Linguística, v. 14, n. 1, p. 156-164, 2013.

FREITAG, R. M. K. Amostras sociolinguísticas: probabilísticas ou por conveniência? Revista de Estudos da Linguagem, v. 26, n. 2, p. 667-686, 2018.

GUEDES, S. Emprego do artigo definido em situação de contato dialetal. Domínios de Lingu@ gem, v. 13, n. 4, p. 1401-1432, 2019.

G1. Jornal Nacional. Pela primeira vez, negros são maioria nas universidades públicas, diz IBGE. Disponível em: https://g1.globo.com/jornal-nacional/noticia/2019/11/13/pela-primeiravez-negros-sao-maioria-nas-universidades-publicas-diz-ibge.ghtml. Acesso em: 18 out. 2020.

LABOV, W. Principles of linguistic change, volume 1: Internal factors. Oxford: Blackwell, 1994.

LABOV, W. Padrões Sociolinguísticos. Trad. de M. Bagno; M. M. P. Scherre; C. R. Cardoso. São Paulo: Parábola, 2008.

LEE, E. S. Uma teoria sobre a migração. In: MOURA, H. A. de (Coord.). Migração interna: textos selecionados. Fortaleza: Banco do Nordeste do Brasil - BNB, Escritório Técnico de Estudos Econômicos do Nordeste, p. 89-114, 1980.

LUCCHESI, D. The article systems of Cape Verde and São Tomé creole portuguese: general principles and specific factors. Journal of Pidgin and Creole Languages, v. 8, n. 1, p. 81-108, 1993.

OLIVEIRA, A. T. R. Algumas abordagens teóricas a respeito do fenômeno migratório. In: OLIVEIRA, L. A. P.; OLIVEIRA, A. T. R. (Org.). Reflexões sobre os deslocamentos populacionais no Brasil. Brasília: Instituto Brasileiro de Geografia e Estatística, 2011. 
OLIVEIRA, A. T. R. et al. O panorama dos deslocamentos populacionais no Brasil: PNADs e Censos Demográficos. In: OLIVEIRA, L. A. P.; OliVEIRA, A. T. R. (Org.). Reflexões sobre os deslocamentos populacionais no Brasil. Brasília: Instituto Brasileiro de Geografia e Estatística, 2011.

OUSHIRO, L. A acomodação dialetal e a estabilidade de padrões sociolinguísticos na fala adulta. Relatório Científico (Pós-doutorado em Linguística) - Faculdade de Letras, Universidade Federal do Rio de Janeiro, Rio de Janeiro, 2016.

PATIL, I.; POWELL, C. GGSTATSPLOT: “ggplot2”, Based Plots with Statistical Details, 2018.

R CORE TEAM. R: A language and environment for statistical computing. R Foundation for Statistical Computing, Vienna, Austria, 2018. Disponível em: https://www.r-project.org/. Acesso em: 18 jan. 2021.

RIBEIRO, C. C. S. Deslocamento geográfico e padrões de uso linguístico: a variação entre as preposições em ni na comunidade de práticas da Universidade Federal de Sergipe. 88f. Dissertação (Mestrado em Estudos Linguísticos) - Universidade Federal de Sergipe, 2019.

SIQUEIRA, M. Efeitos do contato entre normas na variação linguística: a presença de artigo definido antecedendo possessivos no falar universitário da UFS. Porto das Letras, v. 6, n. 1, p. 8-33, 2020.

SOUZA, G. G. A. Palatalização de oclusivas alveolares em Sergipe. 76f. Dissertação (Mestrado em Letras) - Programa de Pós- Graduação em Letras, Universidade Federal de Sergipe, 2016.

SOUZA NETO, A. F. Realizações dos fonemas /t/ e [d] em Aracaju SE. São Cristóvão: Editora UFS, 2014.

Recebido para publicação em: 13 jul. 2021.

Aceito para publicação em: 26 ago. 2021. 